\title{
Assembling of carbon nanotubes film responding to significant reduction wear and friction on steel surface
}

\author{
Bin Zhang ${ }^{1,2}$ (D) Yong Xue ${ }^{1,3} \cdot$ Li Qiang $^{1,5} \cdot$ Kaixong Gao ${ }^{1,5} \cdot$ Qiao Liu $^{4} \cdot$ \\ Baoping Yang ${ }^{3} \cdot$ Aiming Liang ${ }^{1} \cdot$ Junyan Zhang ${ }^{1}$
}

Received: 6 July 2017/ Accepted: 19 October 2017/Published online: 30 October 2017

(c) The Author(s) 2017. This article is an open access publication

\begin{abstract}
Friction properties of carbon nanotubes have been widely studied and reported, however, the friction properties of carbon nanotubes related on state of itself. It is showing superlubricity under nanoscale, but indicates high shear adhesion as aligned carbon nanotube film. However, friction properties under high load (which is commonly in industry) of carbon nanotube films are seldom reported. In this paper, carbon nanotube films, via mechanical rubbing method, were obtained and its tribology properties were investigated at high load of 5 to $15 \mathrm{~N}$. Though different couple pairs were employed, the friction coefficients of carbon nanotube films are nearly the same. Compared with bare stainless steel, friction coefficients and
\end{abstract}

Bin Zhang and Yong Xue contributed equally to this paper

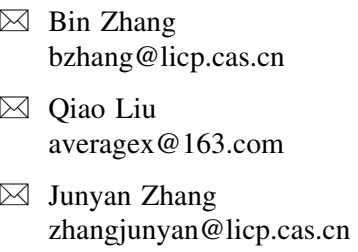

1 R\&D Center of Lubricating and Protecting Materials, Lanzhou Institute of Chemical Physics, Chinese Academy of Sciences, Lanzhou 730000, People's Republic of China

2 Lawrence Berkeley National Laboratory, 1 Cyclotron Road, Berkeley, CA 94720, USA

3 School of Petrochemical Technology, Lanzhou University of Technology, Lanzhou 730050, People's Republic of China

4 Institute of Materials, Ningbo University of Technology, Ningbo 315016, People's Republic of China

5 University of Chinese Academy of Sciences, Beijing 100049, People's Republic of China wear rates under carbon nanotube films lubrication reduced to, at least, $1 / 5$ and 1/(4.3-14.5), respectively. Friction test as well as structure study were carried out to reveal the mechanism of the significant reduction wear and friction on steel surface. One can conclude that sliding and densifying of carbon nanotubes at sliding interface contribute to the sufficient decrease of friction coefficients and wear rates.

Keywords Carbon nanotubes - Friction - Wear - Films . Lubrication

\section{Introduction}

Almost one-third of energy that human used every day is consumed and wasted by friction on moving parts of kinds of machines. So, more than half a century, tribolists tried to low the friction dissipation and they will continue to do it via development of various new lubricating materials. Interestingly, carbon is not only the base of life but also the magical element of which in the form of organic (like oil, alcohol and so on) or inorganic (like brilliant diamond, black coal and graphite, etc.), pushing human society forward. As lubricious materials, carbon nanotubes, discovered by Iijima (1991), is a potentially lubricious material. So far, tribological applications of CNTs include lubrication film, additive and filler (Loyd et al. 2011; Cui et al. 2013a; Schaber et al. 2015; Chen et al. 2005). Kis et al. (2006) reported that multiwall carbon nanotubes shown ultralow friction between nanotube shells. Such ultralow friction or superlubricity properties, recently, is confirmed by Zhang et al. (2013) in centimeters-long double-walled carbon nanotubes under ambient conditions. Rolling and sliding of carbon nanotubes were also studied by two different groups (Buldum and Lu 1999; Falvo et al.1999), 
shown that rolling is more easy than that sliding, but rolling or not, depending on the potential energy barriers (which may be influenced interaction force to the substrates) (Lucas et al. 2009; Qu et al. 2003). The microscale friction properties have also been contravened on the carbon nanotube arrays. Unusually, carbon nanotubes show high shear force which can be employed to mimic gecko foot [110] Kinoshita's (2004) work showed that carbon nanotube forests held high friction properties unrelated to contact faces. But very recently, Westover et al. (2016) reported that vertically aligned carbon nanotubes shown variation friction coefficients due to the restructuring. By the way, many recent studies have focused on carbon nanotubes' modified kinds of antifriction and antiwear materials and have benefits for reduction friction and wear $(\mathrm{Li}$ et al. 2016; Cui et al. 2013b; Liu et al. 2017). In one word, carbon nonotubes shown superlubcity might be using nanoscale mechanics but are more complicated in mocroscale related on state of itself. As we know, so far, there is no any report about friction properties under high load which is commonly conditions in industry.

In present work, we prepared CNTs film directly on bare stainless steel substrate by mechanical rubbing CNTs powder. The tribological properties have been studied under loads of $5-15 \mathrm{~N}$ and the results indicate that the CNTs film exhibits good lubricity and antiwear properties. Compared with bare stainless steel (friction coefficient is oscillation and of about 0.5 and wear rate at $4.5 \times 10^{-5}$ $\mathrm{mm}^{3} / \mathrm{Nm}, 2.5 \times 10^{-5} \mathrm{~mm}^{3} / \mathrm{Nm}$ and $2 \times 10^{-5} \mathrm{~mm}^{3} / \mathrm{Nm}$ to $\mathrm{GCr} 15, \mathrm{Al}_{2} \mathrm{O}_{3}$ and $\mathrm{Si}_{3} \mathrm{~N}_{4}$ balls, respectively), friction coefficients (of about 0.1 ) and wear rates (at $3.1 \times 10^{-6}$ $\mathrm{mm}^{3} / \mathrm{Nm}, 4.5 \times 10^{-6} \mathrm{~mm}^{3} / \mathrm{Nm}$ and $4.6 \times 10^{-6} \mathrm{~mm}^{3} / \mathrm{Nm}$ of steel under carbon nanotubes lubrication to $\mathrm{GCr} 15$, $\mathrm{Al}_{2} \mathrm{O}_{3}$ and $\mathrm{Si}_{3} \mathrm{~N}_{4}$ balls, respectively) reduce to $1 / 5$ and $1 /$ (4.3-14.5), respectively. With and without carbon nanotube film, the friction coefficients show unchanges with the loads. Both Raman spectra and TEM results show that long carbon nanotubes cut off into short ones under the shearing force. In one word, introducing carbon nanotube films sufficiently lowers friction and wear properties, which benefits from the sliding and densifying of carbon nanotubes at sliding interface. Our work shed light on the lubrication design of about carbon nanotubes films in industrial scale.

\section{Experimental}

\section{Preparation of the film}

Carbon nanotubes (CNTs, diameter: 20-50 nm, Length: 5-30 $\mu \mathrm{m})$, purchased from Nanjing XFNANO Materials Tech Co., Ltd. Stainless steel wafers $(40 \times 20 \times 1.7 \mathrm{~mm})$, were obtained by machining with roughness $172 \mathrm{~nm}$. All stainless steel wafers were cleaned by sonication for more than $30 \mathrm{~min}$ in ethanol solution in an ultrasonic bath to remove contaminants, and subsequently blown dry with $\mathrm{N}_{2}$. After that, CNTs film were assembled on bare stainless steel substrates by mechanical rubbing CNTs powder and the process shown in Fig. 1. For a better understanding the friction properties of the CNTs film, graphene film were obtained via the same process.

\section{Characterization}

After deposition, the topographies of CNTs film and graphite film were observed by field emission scanning electron microscopy (FE-SEM, JSM-6701F, JEOL, Japan). Raman spectroscope (LABRAM HR 800 at a wavelength of $532 \mathrm{~nm}(2.3 \mathrm{eV}))$ and high resolution transmission electron microscopy (HRTEM) were applied to reveal the micro-structure of the film before and after the friction tests. The friction-load curves were recorded on a multifunctional material surface performance tester (MFT-4000, China), and the wear data were obtained by three-dimensional surface profiler (MicroXAM-3D).

\section{Tribological Study of the CNTs film and graphene film}

The tribological experiments of as-prepared film were conducted on a multifunctional material surface performance tester with a ball on disk contact geometry under ambient condition $\left(25-28{ }^{\circ} \mathrm{C}\right.$, RH: $\left.42-45 \%\right)$. During this course we chosen $\mathrm{GCr} 15, \mathrm{Al}_{2} \mathrm{O}_{3}, \mathrm{Si}_{3} \mathrm{~N}_{4}$ balls $(\varnothing=5 \mathrm{~mm})$ as the friction pairs, whereas the lower tested samples were mounted onto the flat base and driven to slide reciprocally at a distance of $5 \mathrm{~mm}$. The normal load for tests were 5,10 , 5-15 N, respectively, and reciprocating speeds were all $240 \mathrm{~mm} / \mathrm{min}$. In order to avoid the randomness of experiment results and make it more convinced, all friction experiments were repeatedly performed for more than three times under the same conditions. The friction coefficient for each normal load was obtained by averaging and then plotted curves.

\section{Results}

\section{Characterization of CNTs film and graphene film}

The film in present study prepared via original CNTs without any further processing. The original CNTs with diameters from $20-50 \mathrm{~nm}$ can be distinct by both FESEM and HRTEM (Fig. 2a). HRTEM test show that carbon nanotubes are graphene layered structure (Fig. 2a $a_{1}$ ), with 


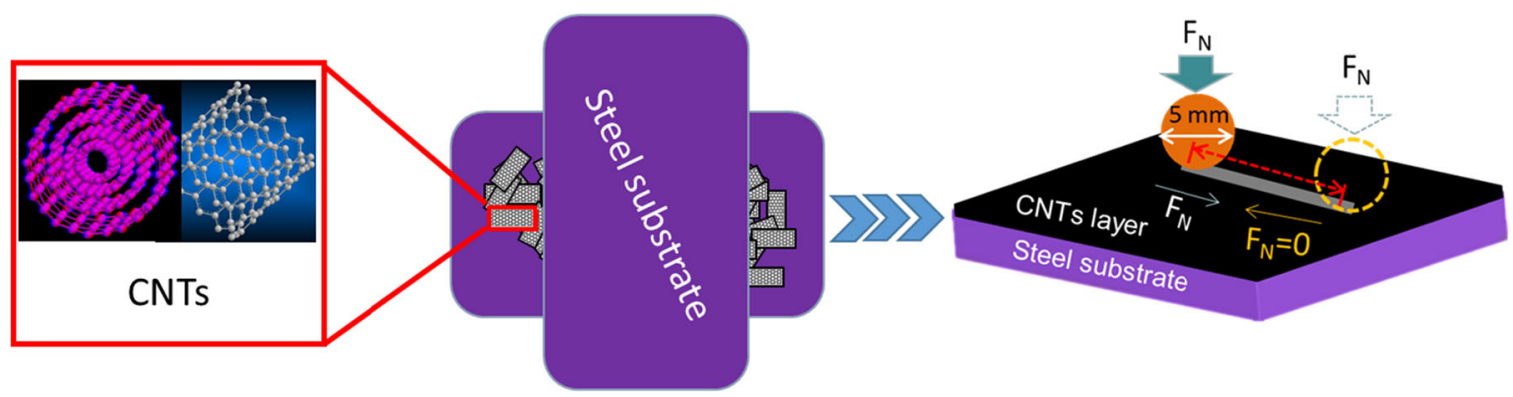

Fig. 1 Schematic of mechanical rubbing for preparation of CNTs film on stainless steel substrate
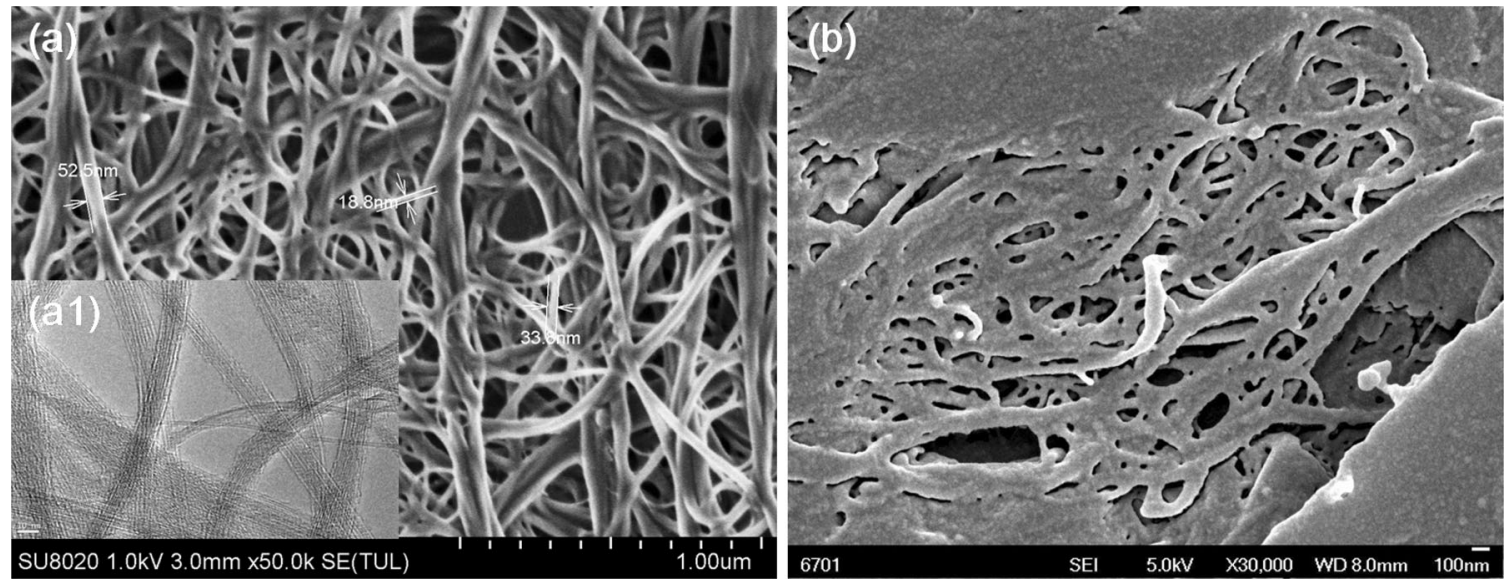

Fig. 2 The FESEM (a) and HRTEM images (a1) of CNTs and FESEM micrograph of CNTs film as-prepared (b)

interlayer space about $0.34 \mathrm{~nm}$. After mechanical rubbing, CNTs are assembled to form dense film mixed with some amorphous structure, i.e., the rubbing force destroyed some of carbon nanotubes in rubbing process (Fig. 2b). Both CNTs and as-prepared films, inspected by Raman spectroscope, show a typical carbon nonotubes Raman features (Fig. 3a), with an obvious G peak at $1570 \mathrm{~cm}^{-1}$ and a D band at $1355 \mathrm{~cm}^{-1}$ (Fig. 3a). Besides, small satellite band at $2730 \mathrm{~cm}^{-1}$, accompanying with new band at $2930 \mathrm{~cm}^{-1}$ are observed.. The $2730 \mathrm{~cm}^{-1}$ band arise from 2D vibration and $2930 \mathrm{~cm}^{-1}$ comes from D + G (S) vibration, due to the increase of defects in CNTs (Sato et al. 1978; Wang et al. 2009).

For the graphene films, one can see from Fig. 4 that sheet structures cover the steel substrate to form a uniform film. HRTEM image show that the nanostructure of the films with a fine graphene crystal structure, and which is proved again by Raman spectra that an obvious G peak at $1581 \mathrm{~cm}^{-1}$ and a D band at $1349 \mathrm{~cm}-1$ can be seen. Besides $\mathrm{G}$ and $\mathrm{D}$ peaks, there are five satellite peaks at 1621, 2457, 2689, 2936, and $3247 \mathrm{~cm}^{-1}$ (Fig. 4a). The $1621 \mathrm{~cm}^{-1}$ peak, usually referred as D' peak, can be observed from defect graphite or graphene, originates from the LO phonons near the $\Gamma$ point (Ferrari 2007; Zólyomi et al. 2011). The rest bands, $2457 \mathrm{~cm}^{-1}$ band are assigned the band as " $q=0$ " branch of double resonance Raman scattering, $2689 \mathrm{~cm}^{-1}$ band arises from 2D vibration, $2936 \mathrm{~cm}^{-1}$ comes from $\mathrm{D}+\mathrm{G}(\mathrm{S})$ vibration which is induced by two TO phonons around the $\mathrm{K}$ point and $3247 \mathrm{~cm}^{-1}$ peak arises from 2D' (Shimada et al. 2005, Antunes et al. 2006).

\section{Tribology properties of the CNTs film and graphene film}

In order to more detailed study of the lubrication mechanism of the CNTs film, here, $\mathrm{GCr} 15, \mathrm{Al}_{2} \mathrm{O}_{3}, \mathrm{Si}_{3} \mathrm{~N}_{4}$ balls ( $\Phi=5 \mathrm{~mm}$ ) were employed as the friction couple pairs. Figure 5 presents the friction coefficients of bare stainless steel and as-prepared CNTs film test coupling with different friction pairs $\left(\mathrm{GCr} 15, \mathrm{Al}_{2} \mathrm{O}_{3}\right.$ and $\mathrm{Si}_{3} \mathrm{~N}_{4}$ Ball) under different loads (Fig. 5a: 5 N, Fig. 5b: $10 \mathrm{~N}$ and Fig. 5c: 5-10-115 N). Figure $5 d$ gives the load adding process from 5 to $15 \mathrm{~N}$. It is obviously that the friction coefficients show no obviously changing with the variation of loads (compared with that of Fig. 5a and b), which means no matter what kinds of the pair materials or the loads are, the friction properties mainly determined by the interface structure between the ball and the substrates. Compared with the friction coefficient of bare stainless steel wafer which is

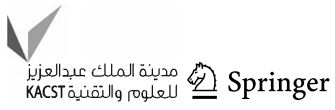



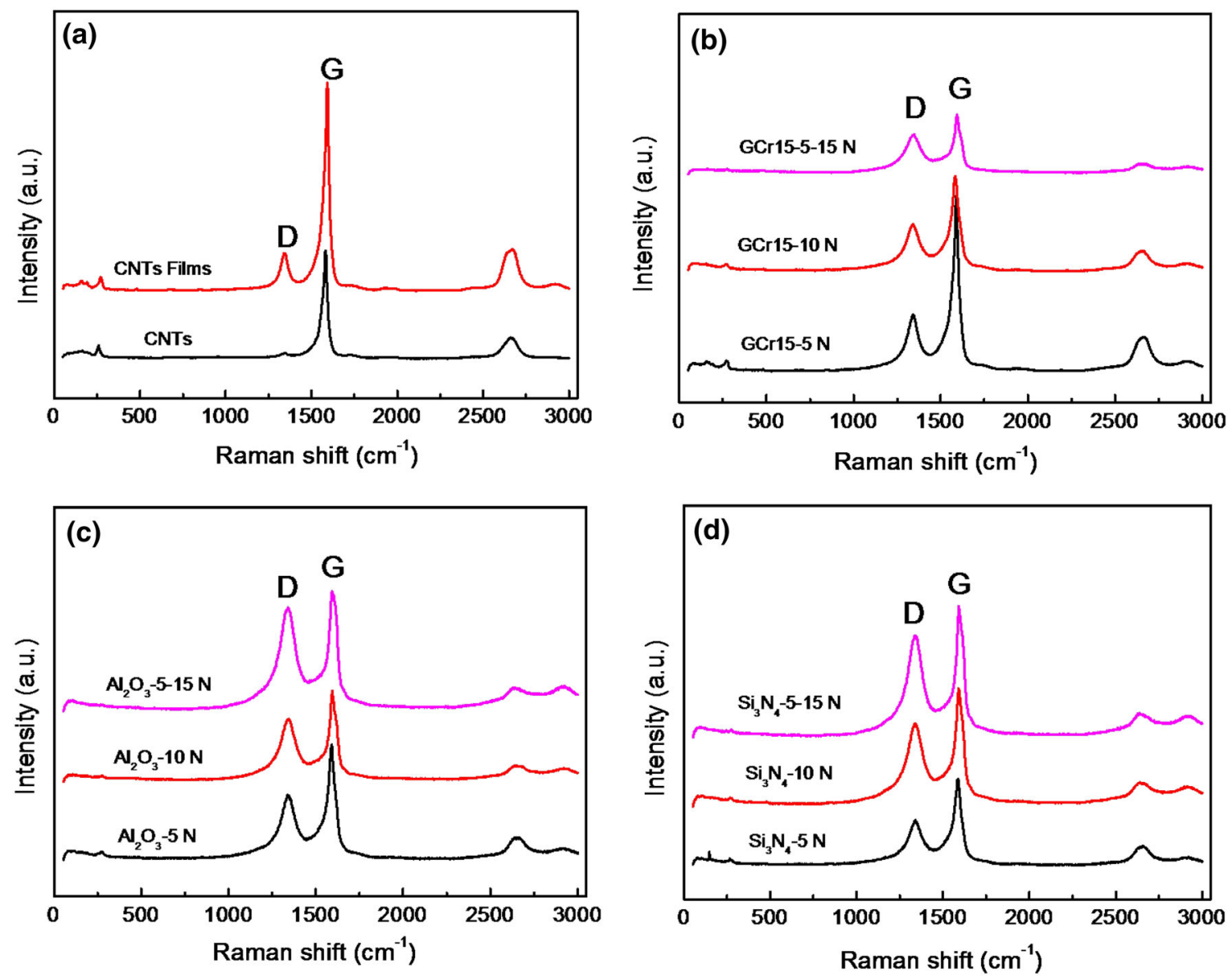

Fig. 3 Raman Spectrum of the raw CNTs (a) and as-prepared film before (a) and after friction test (b, c, d)
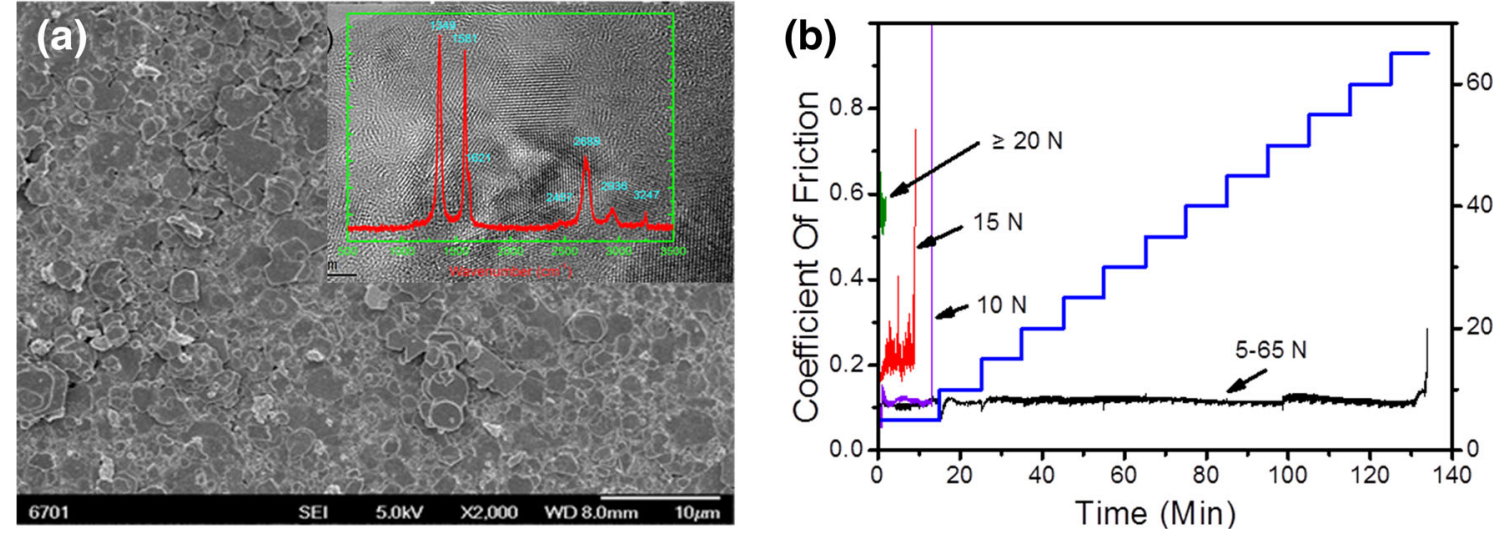

Fig. 4 The FESEM and HRTEM images (a) of graphite films and the corresponding friction properties under different loads (b)

higher (about 0.5) and significantly fluctuating under all test conditions, CNTs film covered substrates show the lower and stable friction coefficient (about 0.1 ). The results indicates that the CNTs film could effectively reduce the friction coefficient of the stainless steel (about from 0.5 to $0.1)$.
Further study of tribology via FESEM displays in Fig. 6. Without CNTS film, severe abrasion can be observed, and which may be caused by abration wear. But under protection of CNTs' films, the wear scars' are smoother and narrower (Fig. 6). The width of the wear scars' are broadening with increase of load with or without protection 

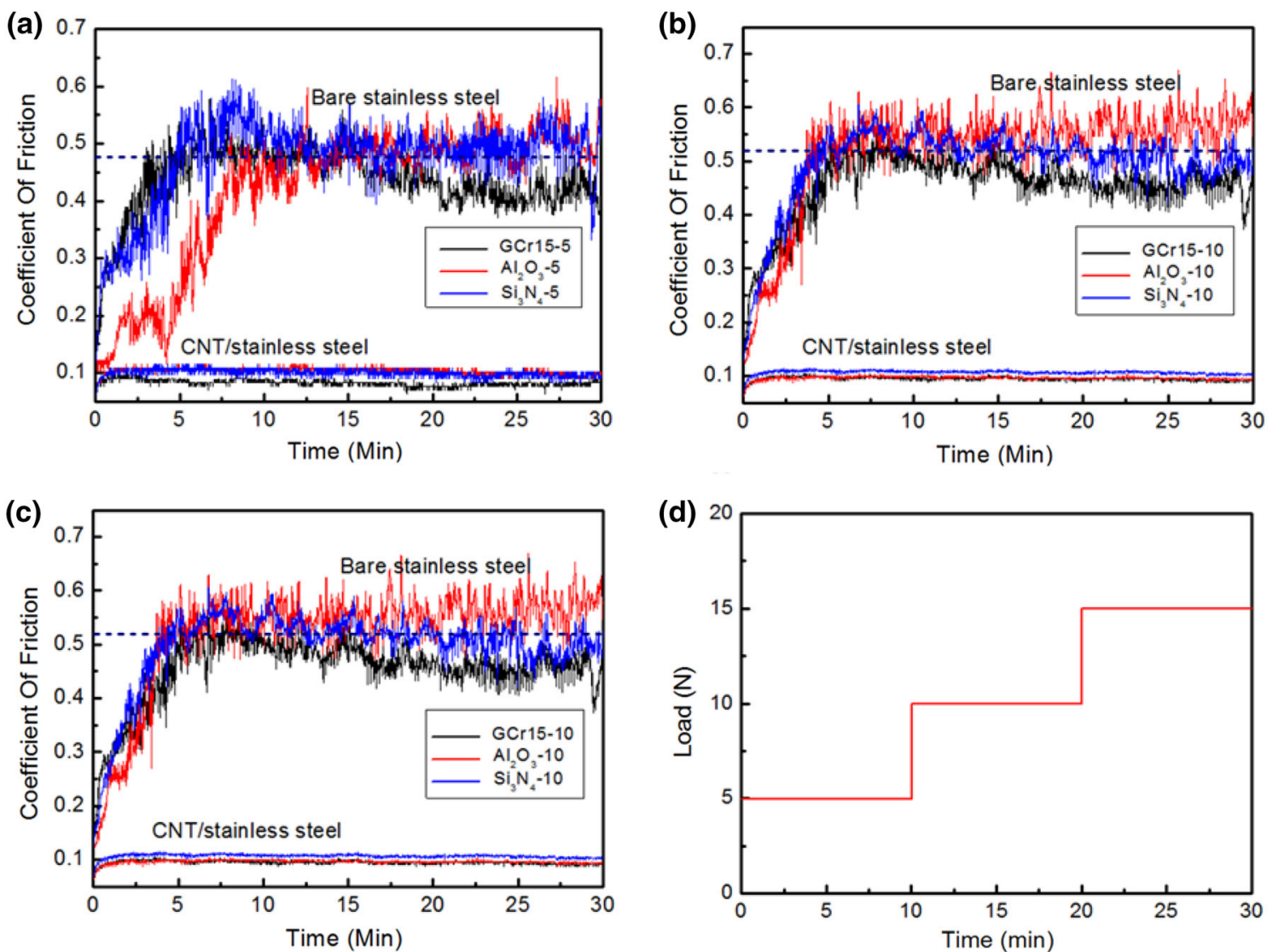

Fig. 5 Friction coefficient curves as a function of the time (a: $5 \mathrm{~N}$, b: $10 \mathrm{~N}$, c: 5-15 N) for bare stainless steel wafer and as-prepared CNTs films test at different friction pairs $\left(\mathrm{GCr} 15, \mathrm{Al}_{2} \mathrm{O}_{3}\right.$ and $\mathrm{Si}_{3} \mathrm{~N}_{4}$ Ball)

of carbon nanotubes, but more gently when introduced of carbon nanotube films. Contact stresses (CS) were calculated from the wear scars and the loads depicted in Fig. 7a. To each couple balls, CS increase with the load increasing. And the CS higher when carbon nanotube films introducing in, indicate that high load resistance can be achieved. However, wear rates show inconsistent trends with or without carbon nanotube films (Fig. 7b). For bare steel, wear rates are increasing with increase of loads, but for the one with carbon nanotube films, wear rates variation are the quite opposite. On the other hand, compared with bare steel, with carbon nanotube films protection, the wear rates reduce to $1 / 4.3,1 / 4.6$ and $1 / 14.5$ at friction test under variation loads ( 5 to $15 \mathrm{~N}$ ), respectively.

But the tribology properties of graphene films are very distinct from carbon nanotube ones. One can see from Fig. $4 \mathrm{~b}$ that the friction coefficient of under load at $5 \mathrm{~N}$ is in accordance well with that of carbon nanotube films. However, when increase the load to $10 \mathrm{~N}$ and to $15 \mathrm{~N}$, the antifriction effects are failure (Fig. 4b). If one noticed that though both films were obtained via rubbing carbon nanotube/graphene, the carbon nanotube film shows an interlocked structure while graphene film gives a flat sheet stacked structure. So the graphene film is easier to be pushed out from the friction interface than the carbon nanotube film that interlocking helps to prevent slip. Interestingly, with 5 or 10 min friction induced densification that graphene film can tolerance high loads (Fig. 4b). More details of about the bearing capacity of graphene film were discussed in other paper.

\section{Discussion}

It is obviously that the friction coefficients and wear rates are tremendously reduced via introduction of carbon nanotube films. On one hand, we notice that the friction coefficients obvious unchanged neither with the couple balls nor with the loads. and the smooth friction curve can be obtained under any loads (Fig. 4c and d). But for graphene film, high loads induced failure of lubricication. That means interlocking of carbon nonatube is more critical that can afford higher loads via hinder sliping. To reveal the lubrication mechanism, the wear debris obtained from couple balls were collected for TEM tests. One can easier to see that before friction tests, micrometers long carbon naotubes (Fig. 8a) with perfect 
Fig. 6 Wear tracks on stainless steel, CNTs/stainless steel and couple balls: $\mathrm{GCr} 15(\mathbf{a}), \mathrm{Al}_{2} \mathrm{O}_{3}$ (b) and $\mathrm{Si}_{3} \mathrm{~N}_{4}$ (c) (note: to every kind of balls, the tops are stainless steel and bottoms are CNTs/stainless steel)
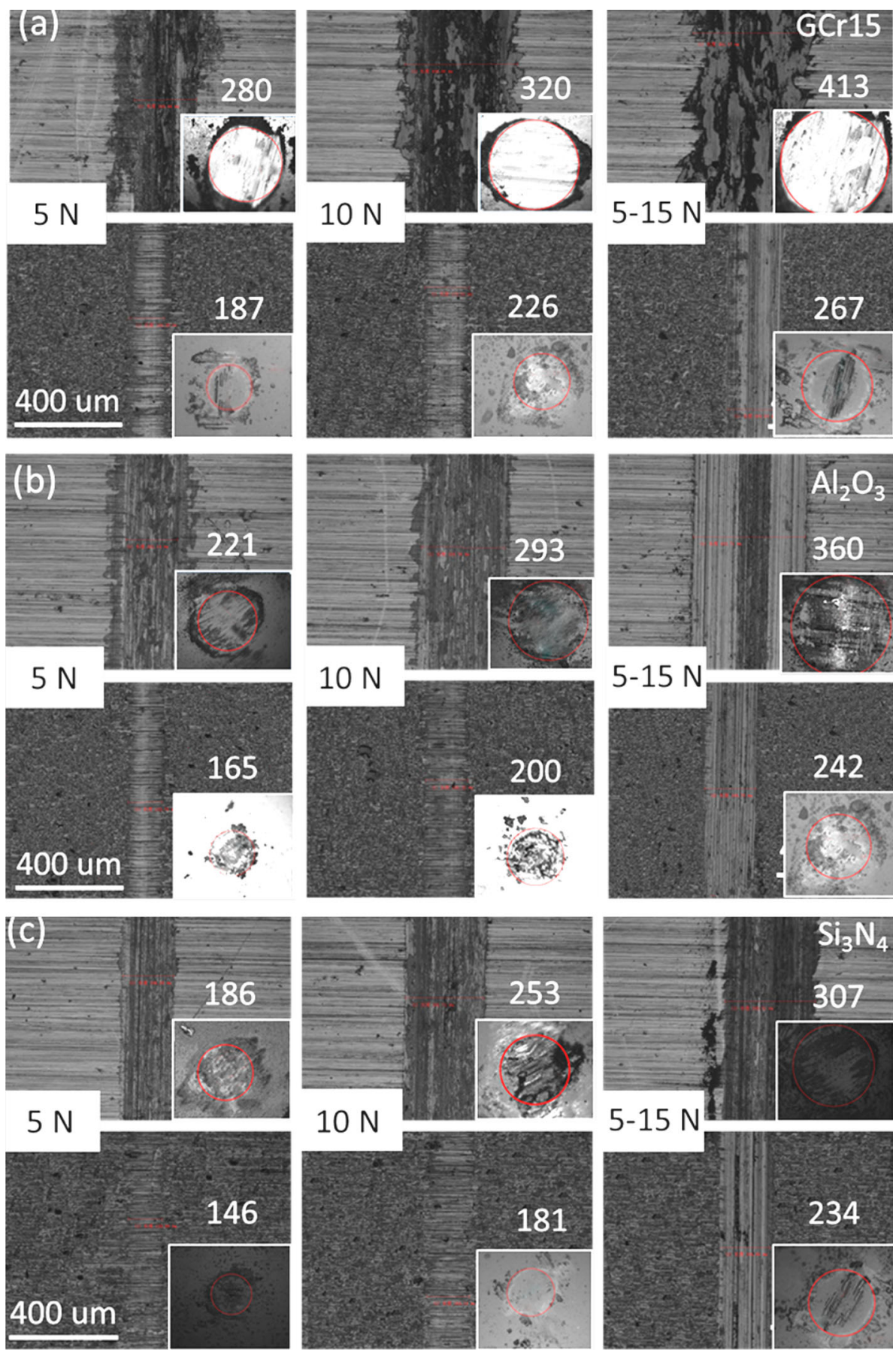

structure (Fig. 1 $1 \mathrm{a}_{1}$ ), but some of the carbon nanotubes cut into pieces due to shear force induced by friction. Short carbon nanotubes mixed with twist long ones could be seen everywhere under TEM scan (Fig. 8b), and we can also find some graphene flakes which might be cracked from short carbon nanotubes (Fig. 8b). Nevertheless, we have not seen much amorphous carbon which might be the short carbon nanotubes are very stiff (Schaber et al. 2015) that can tolerate loads at such scale. Further confirmation of the results can be achieved the Raman spectra. As shown in Fig. 3, though the loads increase to $15 \mathrm{~N}$, the $\mathrm{D}$ and $\mathrm{G}$ peaks position are almost unchanged. However, the intensity of D peak, 2D and $\mathrm{S}$ bands are increasing with load changing. Usually, for the crystal carbon, the increase of $\mathrm{D}$ peak means the defects increasing, so one can expect that $\mathrm{I}_{\mathrm{D}} / \mathrm{I}_{\mathrm{G}}$ would increase with variation of loads (Dresselhaus et al. 2010; Matthews et al. 1999; Ferrari and Basko 2013). Thus, all the peaks (D, G, 2D and $\mathrm{S}$ ) were fitted with Gauss curves, the peak intensity ratios $\left(\mathrm{I}_{\mathrm{D}} / \mathrm{I}_{\mathrm{G}}\right.$ and $\left.\mathrm{I}_{\mathrm{S}} / \mathrm{I}_{2 \mathrm{D}}\right)$ increased suggest that the defects concentration increasing with increase of loads 

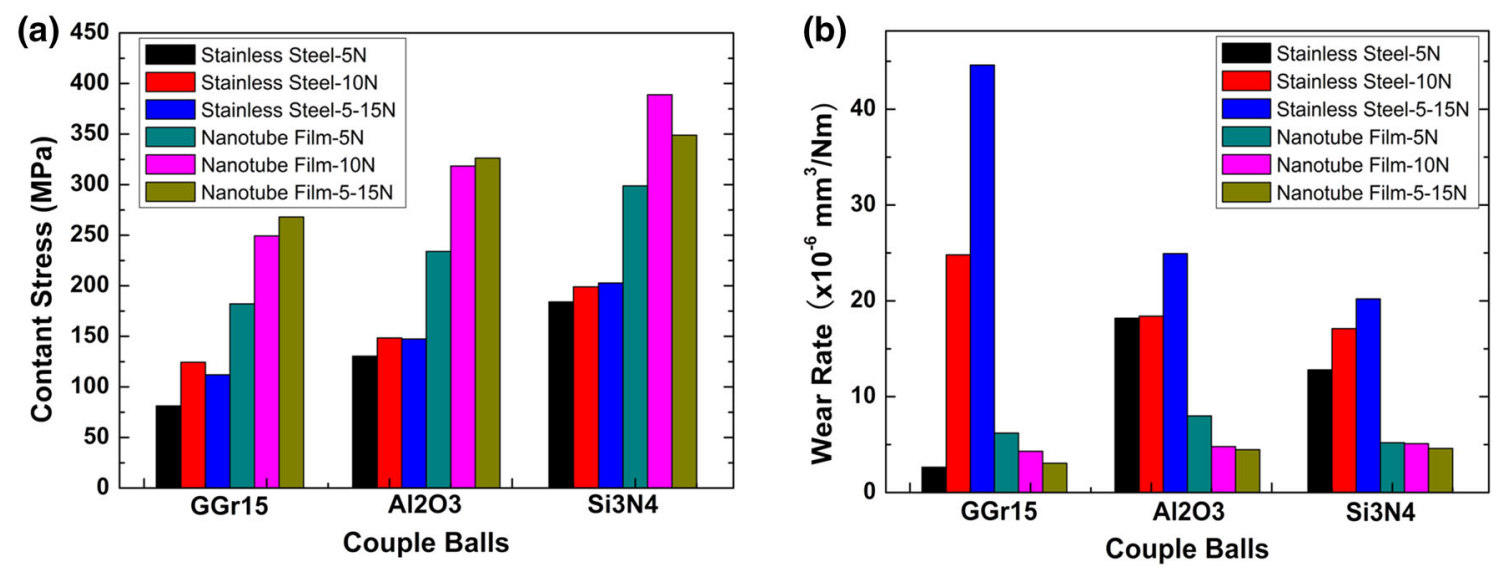

Fig. 7 The wear volumes of the bare stainless steel and the CNTs/stainless steel
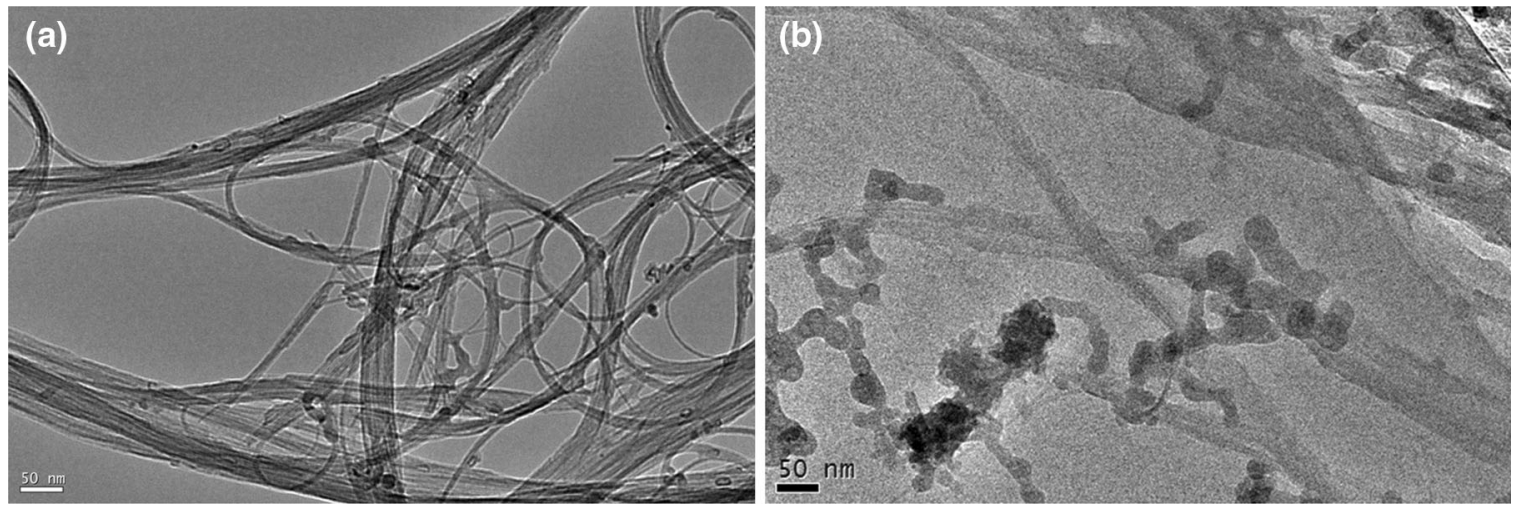

Fig. 8 TEM images of carbon nanotubes before (a) and after friction test under 5-10-15 N loads test (b)
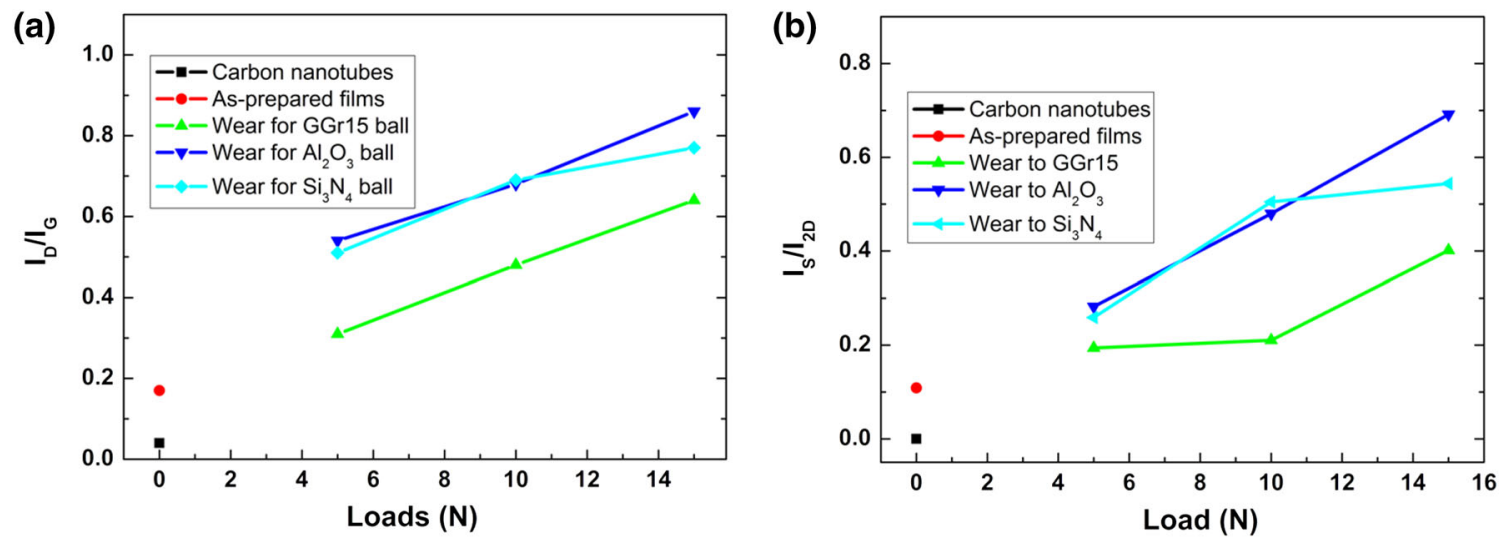

Fig. 9 Raman Spectrum of the raw CNTs (a) and as-prepared film before (a) and after friction test (b, c, d)

(Fig. 9), which agreed with TEM results. On the other hand, it seems no rule for the changes of wear rates to different couple balls, but for certain one, it shows that wear rates increase with loads increasing for bare steel, and decrease with loads increasing for carbon nanotube films. It is largely affected by contact conditions, for bare steels, adhesive wear play a leading role, so with increasing of loads means increase of contact area (Fig. 6), causing more wear and tear (wear rates: $\mathrm{GCr} 15>\mathrm{Al}_{2} \mathrm{O}_{3}>\mathrm{Si}_{3} \mathrm{~N}_{4}$, Fig. 7b). For carbon nonotube films, comparably, adhesive wear is hindered and sliding between carbon nonatubes are playing major role during friction, that is why the couple balls are no obvious wear scars, and the wear rates $\left(\mathrm{Al}_{2} \mathrm{O}_{3}>\mathrm{Si}_{3} \mathrm{~N}_{4}>\mathrm{GCr} 15\right)$ look like deformations of hardness of couple balls (the micro hardnesses are 6.1, 27, and 24.5 GPa for $\mathrm{GCr} 15, \mathrm{Al}_{2} \mathrm{O}_{3}$ and $\mathrm{Si}_{3} \mathrm{~N}_{4}$, respectively) and loads. 


\section{Conclusion}

CNTs films were fabricated directly on the 201 stainless steel wafer by mechanical rubbing CNTs powder. And the friction tests carried out under 5-15 N loads to GCr15, $\mathrm{Al}_{2} \mathrm{O}_{3}$ and $\mathrm{Si}_{3} \mathrm{~N}_{4}$ couple balls with diameter of $5 \mathrm{~mm}$. It is believed that introducing carbon nanotube film is sufficiently reducing the friction and wear almost to $1 / 5$ and $1 /$ (4.3-14.5), respectively. Combined tribology, TEM and Raman results, one can conclude that the friction coefficients are unchanged neither with couples ball nor with loads. It is showing that at such loads scale, shortening the carbon nanotubes by shear force as well as sliding between them play important role to reduce friction and wear. Comparably, the wear rates $\left(\mathrm{Al}_{2} \mathrm{O}_{3}>\mathrm{Si}_{3} \mathrm{~N}_{4}>\mathrm{GCr} 15\right)$ look like deformations of hardness of couple balls (the micro hardnesses are 6.1,27, and 24.5 GPa for GCr15, $\mathrm{Al}_{2} \mathrm{O}_{3}$ and $\mathrm{Si}_{3} \mathrm{~N}_{4}$, respectively) and loads after introducing of carbon nanotubes.

Acknowledgements This work is supported by CVS "Light of West China" Program, Youth Innovation Promotion Association CAS (Grant no. 2017459), the China Scholarship Council (File no. 201604910183), the National Natural Science Foundation of China (Grant no. 51205383) and Natural Science Foundation of Ningbo (Nos. 2015A610241 and 2016A610109).

Open Access This article is distributed under the terms of the Creative Commons Attribution 4.0 International License (http:// creativecommons.org/licenses/by/4.0/), which permits unrestricted use, distribution, and reproduction in any medium, provided you give appropriate credit to the original author(s) and the source, provide a link to the Creative Commons license, and indicate if changes were made.

\section{References}

Antunes EF, Lobo AO, Corat EJ, Trava-Airoldi VJ, Martin AA, Veríssimo C (2006) Comparative study of first-and second-order Raman spectra of MWCNT at visible and infrared laser excitation. Carbon 44:2202-2207

Buldum A, Lu JP (1999) Atomic scale sliding and rolling of carbon nanotubes. Phy Rev Lett 83:5050

Chen CS, Chen XH, Xu LS, Yang Z, Li WH (2005) Modification of multi-walled carbon nanotubes with fatty acid and their tribological properties as lubricant additive. Carbon 43:1660-1666

Cui LJ, Geng HZ, Wang WY, Chen LT, Gao J (2013a) Functionalization of multi-wall carbon nanotubes to reduce the coefficient of the friction and improve the wear resistance of multi-wall carbon nanotube/epoxy composites. Carbon 54:277-282

Cui LJ, Geng HZ, Wang WY, Chen LT, Gao J (2013b) Functionalization of multi-wall carbon nanotubes to reduce the coefficient of the friction and improve the wear resistance of multi-wall carbon nanotube/epoxy composites. Carbon 54:277-282

Dresselhaus MS, Jorio A, Hofmann M, Dresselhaus G, Saito R (2010) Perspectives on carbon nanotubes and graphene Raman spectroscopy. Nano Lett 10:751-758
Falvo MR, Taylor Ii R, Helser A, Chi V, Brooks FP Jr, Washburn S, Washburn S, Superfine R (1999) Nanometre-scale rolling and sliding of carbon nanotubes. Nature 397:236-238

Ferrari AC (2007) Raman spectroscopy of graphene and graphite: disorder, electron-phonon coupling, doping and nonadiabatic effects. Solid State Commun 143:47-51

Ferrari AC, Basko (2013) DM Raman spectroscopy as a versatile tool for studying the properties of graphene. Nature Nanotech $8: 235-246$

Iijima S (1991) Helical microtubules of graphitic carbon. Nature 354:56-58

Kinoshita H, Kume I, Tagawa M, Ohmae N (2004) High friction of a vertically aligned carbon-nanotube film in microtribology. Appl Phys Let 85:2780

Kis A, Jensen K, Aloni S, Mickelson W, Zettl A (2006) Interlayer forces and ultralow sliding friction in multiwalled carbon nanotubes, low-friction nanoscale linear bearing realized from multiwall carbon nanotubes. Phy Rev Lett 8:025501

Li Q, Church JS, Naebe M, Fox BL (2016) Interfacial characterization and reinforcing mechanism of novel carbon nanotube-carbon fibre hybrid composites. Carbon 109:74-86

Liu DG, Sun J, Gui ZX, Song KJ, Luo LM, Wu YC (2017) Super-low friction nickel based carbon nanotube composite coating electrodeposited from eutectic solvents. Diam Relat Mater 74:229-232

Loyd A, Hemond J, Martens R (2011) Preliminary Investigation of Graphite, Graphene and Carbon Nanotubes (CNT's) as Solid State Lubricants [A], 2011 IEEE 57th Holm Conference on Electrical Contacts (Holm)[C]. IEEE, 1-9

Lucas M, Zhang X, Palaci I, Klinke C, Tosatti E, Riedo E (2009) Hindered rolling and friction anisotropy in supported carbon nanotubes. Nature mater 8:876-881

Matthews MJ, Pimenta MA, Dresselhaus G, Dresselhaus MS, Endo M (1999) Origin of dispersive effects of the Raman D band in carbon materials. Phys Rev B 5959:R6585(R)

Qu L, Dai L, Stone M, Xia Z, Wang ZL (2003) Carbon nanotube arrays with strong shear binding-on and easy normal lifting-off. Science 322:238-242

Sato Y, Kamo M, Setaka N (1978) Raman spectra of carbons at $2600-3300 \mathrm{~cm}^{-1}$ region. Carbon 16:279-280

Schaber CF, Heinlein T, Keeley G, Schneider JJ, Gorba SN (2015) Tribological properties of vertically aligned carbon nanotube arrays. Carbon 94:396-404

Shimada T, Sugai T, Fantini C, Souza M, Cançado LG, Jorio A, Pimentab MA, Saito R, Grüneis A, Dresselhaus G, Dresselhaus MS, Ohno Y, Mizutani T, Shinohara H (2005) Origin of the $2450 \mathrm{~cm}^{-1}$ Raman bands in HOPG, single-wall and double-wall carbon nanotubes. Carbon 43:1049-1052

Wang H, Robinson JT, Li X, Dai H (2009) Solvothermal Reduction of chemically exfoliated graphene sheets. J Am Chem Soc 131:9910-9911

Westover AS, Choi J, Cui K, Ishikawa T, Inoue T, Xiang R (2016) Load dependent frictional response of vertically aligned singlewalled carbon nanotube films. Scripta Mater 125:63-67

Zhang R, Ning Z, Zhang Y, Zheng Q, Chen Q, Xie H, Zhang Q, Qian W, Wei F (2013) Superlubricity in centimetres-long doublewalled carbon nanotubes under ambient conditions. Nature mater 8:912-916

Zólyomi V, Koltai J, Kürti J (2011) Resonance Raman spectroscopy of graphite and graphene. Phys Status Solidi B 248:2435-2444

\section{Publisher's Note}

Springer Nature remains neutral with regard to jurisdictional claims in published maps and institutional affiliations. 